\title{
Changes of Population, Built-up Land, and Cropland Exposure to Natural Hazards in China from 1995 to 2015
}

\author{
Yimin Chen $^{1,2} \cdot$ Wei Xie ${ }^{1,2} \cdot$ Xiaocong $\mathrm{Xu}^{1,2}$
}

Published online: 16 December 2019

(C) The Author(s) 2019

\begin{abstract}
By using the latest China population grid and land-use data, we assess the changing exposure of China's population and land uses to the hazards of storm surges, droughts, earthquakes, floods, and landslides from 1995 to 2015. We found that the single-hazard areas and the multihazard areas covered $43 \%$ and $26 \%$ of China's territory, respectively. Population grew faster in the hazard-prone areas than in the non-hazard areas. Built-up area expanded more rapidly in the areas prone to earthquakes and landslides. Cropland changed rapidly in many hazard-prone areas. The hazard-prone areas affected by floods featured the highest cropland loss rates, while the areas prone to earthquakes and landslides featured the highest cropland growth rates. We detected areas with significant exposure changes by using hot spot analysis. It was found that population and built-up land in the Pearl River Basin were increasingly exposed to storm surges, floods, and landslides. The Haihe River Basin and Huaihe River Basin also showed a consistent increase of population and built-up land exposure to droughts and earthquakes. These findings can provide a foundation for the design and implementation of protection and adaptation strategies to improve the resilience of Chinese society to natural hazards.
\end{abstract}

Keywords China - Exposure to natural hazards · Population change $\cdot$ Built-up land · Cropland

Xiaocong Xu

xuxiaocong@mail.sysu.edu.cn

1 School of Geography and Planning, Sun Yat-sen University, Guangzhou 510275, China

2 Guangdong Key Laboratory for Urbanization and Geosimulation, Sun Yat-sen University, Guangzhou 510275, China

\section{Introduction}

Natural hazards worldwide have caused economic losses of billions of US dollars and affected millions of people annually in recent decades (UNISDR 2012). Risk reduction of natural hazards has become a critical component of the sustainable development of human society (Tian et al. 2015; UNISDR 2015). While global population growth and urbanization are accelerating, human settlements and livelihoods are expected to be increasingly exposed to natural hazards (UNDESA 2016). Due to global climate changes, intensified natural hazards and extreme events will pose growing challenges globally for many countries and regions in the prevention and mitigation of economic and social disruptions (Jongman et al. 2012; Güneralp et al. 2015; Blöschl et al. 2017; Huang et al. 2017).

China is among the most rapidly urbanizing countries in the world (UNDESA 2016; Liu et al. 2018). As the world's largest developing country with a middle level income, China is heavily exposed to a wide range of natural hazards, including cyclones, earthquakes, landslides, floods, and droughts (Neumann et al. 2015; Yang et al. 2015). Han et al. (2016) summarized the occurrence of natural hazards in China for 1985-2014 and found that storms and floods were the most frequent hazards, followed by landslides and droughts. China incurs greater damages from natural hazards than most other countries in the world (Lo et al. 2015). Riverine floods, for example, have inflicted tens of thousands of deaths and affected approximately 1.5 billion victims in China during the past two decades (CRED 2019). China is also vulnerable to droughts, even in its humid areas (Wu et al. 2018). The 2009 drought in China caused losses of more than RMB 150 billion yuan (He et al. 2013). About one-fifth of the deadliest earthquakes in recorded history have occurred in China (Holzer and 
Savage 2013). The 2008 Wenchuan Earthquake caused more than 69 thousand deaths and made millions of people homeless (Liu and Sun 2009). Geohazards including landslides have caused severe losses and casualties in both the less developed mountainous regions and the most prosperous areas in China, such as Shenzhen City (Yin et al. 2016).

China is undergoing rapid social and economic changes. A timely and spatially explicit estimation of settlement and land use exposure to multiple natural hazards can, therefore, provide a knowledge base for promoting risk reduction and mitigation. Recent studies have provided important findings of exposure and vulnerability to different natural hazards (for example, storms, floods, landslides, droughts, and earthquakes) in China. Liang et al. (2017) found a substantial increase of elderly people exposure (over 86\%) in the areas prone to storm hazards. Sajjad et al. (2018) predicted that the number of people exposed will double in China's coastal areas that are under current sea level rise by 2100 , reaching a total of 10 million. Fang et al. (2018) and Du et al. (2018) conducted research to investigate the changes of population and built-up land in China's flood-prone areas. Miao et al. (2018) identified the provinces south of the Yellow River as the regions with relatively higher population vulnerability to landslides. Zhang et al. (2019) assessed the resilience to landslides in Shenzhen, one of the biggest cities in China. Pei et al. (2018) suggested a declining trend of drought risk in Heilongjiang Province in Northeast China. Sun et al. (2017) provided projections of future changes in population exposure to droughts for the Haihe River Basin, with a decrease of $30 \%$ and an increase of $75 \%$ in the $1.5{ }^{\circ} \mathrm{C}$ and $2.0^{\circ} \mathrm{C}$ global warming scenarios, respectively. China is also facing great risks of earthquakes (He et al. 2016; Huang et al. 2019). Wu et al. (2017) concluded that roughly $15 \%$ of China's asset values and $14 \%$ of GDP were in areas prone to earthquakes. Regarding the global integrated assessment of multiple hazards, Shi et al. (2015) developed a total risk index and a multi-hazard risk index to map the risks for population and property.

Despite a growing body of literature focusing on exposure to hazards at different scales in China, few analyses have been conducted to estimate exposure to multiple hazards at the national scale. Many regions in China are subject to multiple hazards that potentially lead to greater damages and losses than a single type of hazard (Komendantova et al. 2014; Jaimes et al. 2015). For these regions, the investigation and analysis of exposure to multiple hazards is essential for achieving an effective reduction of hazard risks (Kappes et al. 2012; Ming et al. 2015).

The aim of this study is to use recently released data to assess the exposure of China's population, built-up land, and cropland to multiple hazards from 1995 to 2015 . The selection of built-up land and cropland as two representative land use types is based on their importance to human societies. As China is increasingly urbanized, built-up areas are becoming the major settlements of China's population and contain important infrastructures and facilities, while cropland provides the food supply that is fundamental to the sustainable development of human societies. Natural hazards such as floods damage urban infrastructure, and droughts exert great pressure on foundations, pipes, and joints that causes instability problems for the infrastructure in an urban environment (Güneralp et al. 2015). Landslide and earthquake hazards can create even more serious damages in rural areas. Earthquakes not only destroy irrigation facilities and cropland vegetation (Hualou and Jian 2010; Cui et al. 2012), but also reduce the capacity of soil conservation that impairs the productivity of cropland (Rao et al. 2016).

We attempt to depict the changes in the exposure of China's population, built-up land, and cropland to the hazards of storm surges, droughts, earthquakes, floods, and landslides. We investigate whether population and land use change more rapidly in hazard-prone areas. To this end, we use two analytical methods, which respectively estimate the changes of population and land uses exposed to hazards in different zones, and identify the local areas with significantly increased/decreased exposure to multiple hazards at the subbasin level. Finally, we discuss the findings and their policy implications.

\section{Methodology}

In this section, we provide the sources of population data, land-use data, drainage data, and hazard data. We also explain the method to assess the change of exposure to the selected hazard types.

\subsection{Data Sources}

In this study, we focused on the mainland of China and do not include Hong Kong, Macao, and Taiwan in our analysis due to the lack of consistent data. We used the population data (Fig. 1a-c) and land-use data for the years 1995, 2005, and 2015, provided by the Resource and Environment Data Cloud Platform (RESDC), Data Center for Resources and Environmental Sciences, Chinese Academy of Sciences (CAS). The population data have a spatial resolution of $1 \mathrm{~km}$. The land-use data include the categories cropland, forest, grassland, water, built-up land, and unused land, and have a spatial resolution of $30 \mathrm{~m}$. We extracted cropland and built-up land for our analysis (Fig. 1d-f).

We used the drainage basin data in vector format. This dataset was developed by Masutomi et al. (2009) using 

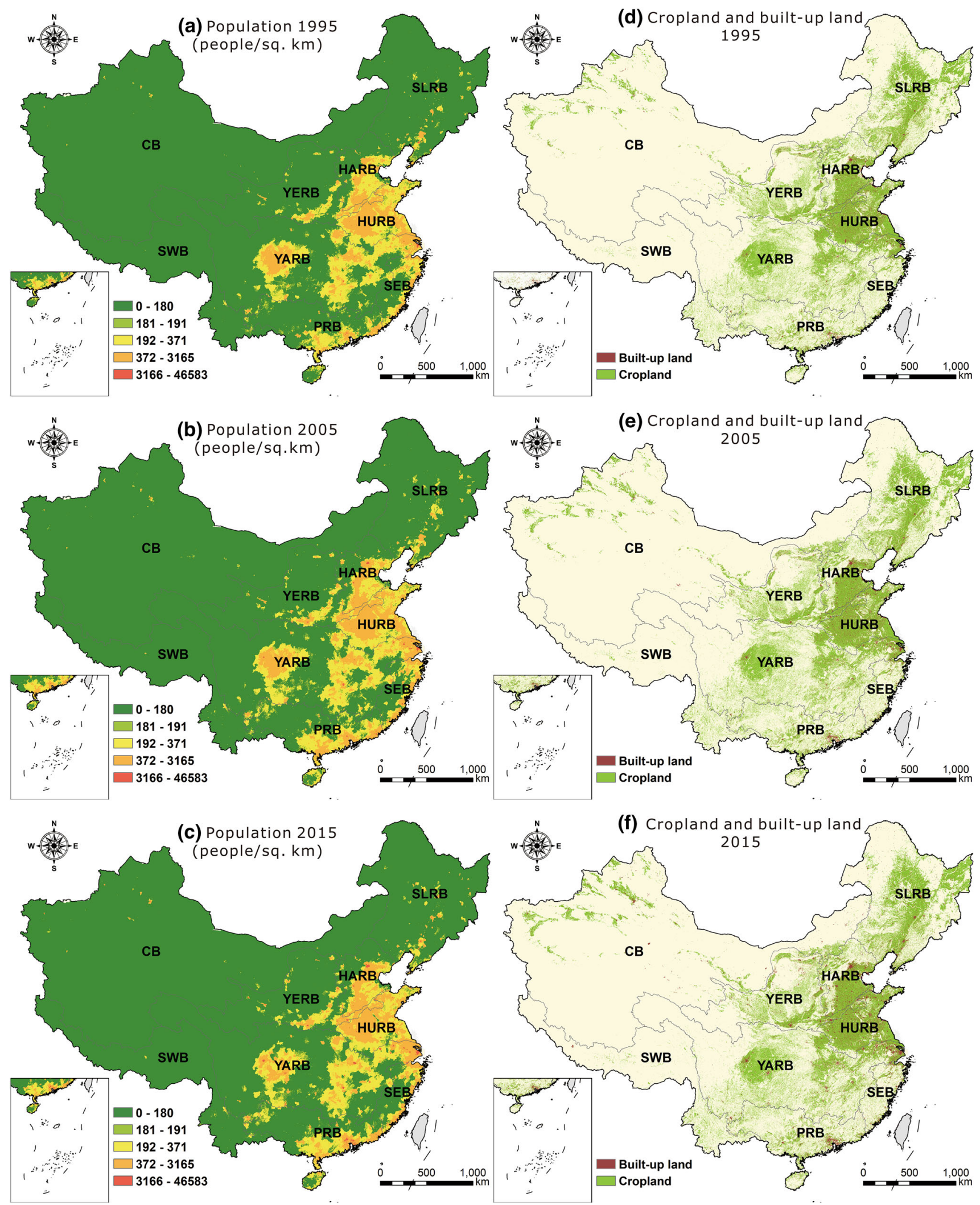

Fig. 1 Population and land-use in China for the years 1995, 2005, and 2015. $C B$ Continental basin, YERB yellow river basin, $H A R B$ Haihe river basin, $S L R B$ Songhua-Liaohe river basin, $S W B$ southwest basin, YARB Yangtze river basin; HURB Huaihe river basin, $P R B$ pearl river basin, $S E B$ southeast basin 
high-resolution digital elevation model (DEM) data, and can be downloaded from Center for Global Environmental Research (Table 1). The drainage basin data provide a detailed description of the sub-basins in China and have a better quality than the conventional HYDRO1k dataset. An individual subbasin is a relatively closed system and a natural unit of ecosystem. Cheng and Li (2015) suggested that watersheds of basins are relevant units for earth system science, not only because they possess the complexity of land surface systems, but also because they connect to administrative boundaries at different levels as socioeconomic activities often take place along major rivers. A relevant example is presented by Güneralp et al. (2015), who investigated future changes of urban land exposure to floods and droughts. Therefore, we use sub-basins as units in our analysis to identify the changes of exposure to different hazards.

We collected the hazard frequency data from the Global Risk Data Platform and focused on five hazard types: cyclone-related storm surges, droughts, earthquakes, floods, and landslides. The datasets involved in this analysis are summarized in Table 1. The storm surge frequency data were developed based on the dataset of historical cyclone tracks and the modeling of cyclone movements through time. The data provide the estimated frequency of cyclone-related (Saffir-Simpson category) storm surges per 1000 years. The drought frequency data include the estimated annual global drought distribution, which was generated mainly based on the standardized precipitation index. Here the drought hazard refers to meteorological droughts. Drought events refer to areas with a monthly precipitation lower than $50 \%$ of the median precipitation of the historical period for at least three consecutive months. The earthquake frequency data include the estimated number of earthquake events of Modified Mercalli Intensity categories higher than 9 per 1000 years. The flood frequency data were developed mainly based on hydrological modeling using HydroSHEDS datasets and the historical floods obtained from the Dartmouth Flood Observatory (DFO). This dataset estimated the average frequency of flood events per 100 years. The landslide frequency data include two raster layers that represent landslides triggered by earthquakes and by precipitation, respectively. They were produced by using a landslide hazard assessment model that considers the triggering factors of slope, geological conditions, soil moisture, vegetation cover, and seismic and precipitation conditions. These datasets offer the estimated annual frequency of earthquake- and precipitation-related landslides, respectively. The frequency estimation was based on the historical events of earthquakes and extreme monthly rainfall that triggered landslides (Nadim et al. 2013). They were summed to one single raster layer in our analysis to represent the landslide frequency.

All spatial datasets are projected using a Universal Transverse Mercator (UTM) map projection with reference to the World Geodetic System-WGS 1984, UTM zone $49 \mathrm{~N}$. The original built-up land and cropland maps were transformed into $1-\mathrm{km}$ grid data with the grid values representing the areal fraction of built-up land and cropland, respectively. The $10-\mathrm{km}$ drought frequency data were resampled into a $1-\mathrm{km}$ resolution map, in which the $1-\mathrm{km}$ grids would have the same values if they were within the same $10-\mathrm{km}$ grid in the original drought frequency data.

\subsection{Methods}

In this section, we explain the classification of China's territory into different hazard-prone areas according to hazard frequency. We also specify how to measure the exposure of population, built-up land, and cropland to hazards.

Table 1 Description of the datasets used in the analysis of the changes of population, built-up land, and cropland exposure to natural hazards in China from 1995 to 2015

\begin{tabular}{|c|c|c|}
\hline Dataset & Resolution & Sources \\
\hline Population grid & $1 \mathrm{~km}$ & Resource and Environment Data Cloud Platform (RESDC), Data Center \\
\hline Land use & $30 \mathrm{~m}$ & for Resources and Environmental Sciences, Chinese Academy of Sciences (http://www.resdc.cn) \\
\hline Drainage basins & - & Center for Global Environmental Research (http://www.cger.nies.go.jp/db/gdbd/gdbd_index_e.html) \\
\hline Storm surge frequency & $\sim 1 \mathrm{~km}$ & Global Risk Data Platform (https://preview.grid.unep.ch) \\
\hline Drought frequency & $\sim 10 \mathrm{~km}$ & \\
\hline Earthquake frequency & $\sim 1 \mathrm{~km}$ & \\
\hline Flood frequency & $\sim 1 \mathrm{~km}$ & \\
\hline Landslide frequency & $\sim 1 \mathrm{~km}$ & \\
\hline
\end{tabular}




\subsubsection{Classification of Hazard-Prone Areas}

Based on the hazard frequency data, we classified the territory of the mainland of China into three types of zones according to their frequency level for each hazard type. They are non-hazard areas (NHAs), hazard areas with relatively low-frequency (LF-HAs), and high frequency hazard areas (HF-HAs), respectively. The determination of non-hazard areas (NHAs) and hazard-prone areas is similar to the approach used in previous studies (Jongman et al. 2012; Güneralp et al. 2015; Du et al. 2018). In this study, NHAs refer to areas with zero hazard frequency and the hazard areas (HAs) refer to those with hazard frequency greater than zero. For each hazard type, the hazard areas were further separated into LF-HAs and HF-HAs. As suggested by recent studies (Jiang 2013, 2015), for many geographic phenomena, the mean value is an adequate cutoff point for the determination of "low" and "high." Therefore, for each hazard type, LF-HAs and HF-HAs were determined using the mean frequency value, with LFHAs referring to areas with hazard frequency lower than the mean value and HF-HAs referring to areas with hazard frequency greater than the mean value. By using these classifications, the population number and land-use areas were summarized and compared throughout the country. The overall change rate from 1995 to 2015 and annual change rate of population and land use in the NHAs, LFHAs, and HF-HAs, respectively, were calculated as follows:

$R_{t_{0} \rightarrow t_{1}}=\left(\frac{N_{t_{1}}-N_{t_{0}}}{N_{t_{0}}}\right) \times 100 \%$

$r_{t_{0} \rightarrow t_{1}}=\left(\sqrt[t_{1}-t_{0}]{\frac{N_{t_{1}}}{N_{t_{0}}}}-1\right) \times 100 \%$

where $R$ and $r$ refer to the overall change rate from 1995 to 2015 and annual change rate, respectively; $N$ is the population number (or land-use areas).

\subsubsection{Exposure Evaluation Method}

Exposure is an estimation of population, property, or other interests that would be subject to natural hazards (LernerLam 2007). We evaluate the exposure of population, builtup land, and cropland to the five selected hazards. Following Peduzzi et al. (2009), we calculated population exposure to a certain hazard type using Eq. 3:

$P E_{i, j}=P_{i} \times F_{i, j}$

where $P E_{i, j}$ represents the population exposure at grid $i$ to hazard $j ; P_{i}$ and $F_{i, j}$ are population and the frequency of hazard $j$ at grid $i$, respectively. The calculation of $P E_{i, j}$ suggests that population living in a grid with a higher occurrence of hazards will be at a higher risk, or that hazards occurring in a grid with a greater population will cause more serious impacts. Land use exposure was evaluated with respect to built-up land and cropland. Exposure of these two land uses was evaluated as follows (Güneralp et al. 2015):

$L E_{i, j}=L_{i} \times F_{i, j}$

where $L E_{i, j}$ represents the exposure of built-up land or cropland at grid $i$ to hazard $j ; L_{i}$ is the land area of built-up land or cropland at grid $i$. The exposure of population, built-up land, and cropland at the grid level was summed up for each sub-basin. The sub-basin level changes of exposure were calculated as follows:

$\Delta E_{t_{0} \rightarrow t_{1}}=E_{t_{1}}-E_{t_{0}}$

where $E_{t_{0}}$ and $E_{t_{1}}$ are sub-basin level exposure (of population, cropland, or built-up land) at time $t_{0}$ and $t_{1}$. Based on the results of $\Delta E_{t_{0} \rightarrow t_{1}}$, we apply the tool of Hot Spot Analysis in ArcMap 10.5 to detect the local areas with significantly increased/decreased exposure. This tool works by calculating the Getis-Ord Gi* statistic for each subbasin. It yields the significant hot/cold spot areas of $\Delta E_{t_{0} \rightarrow t_{1}}$ according to the $\mathrm{z}$-scores and $p$-values of the results. The hot spot areas indicate where significantly increased exposure occurs and vice versa for the cold spot areas. In this study, we used the Queen neighborhood rule and a threshold of 90\% confidence for the Hot Spot Analysis.

\section{Results and Discussion}

In this section, we present the results of exposure change analysis by different hazards. We show the change of population, built-up land, and cropland in the NHAs, LFHAs, and HF-HAs for each hazard type. We illustrate the hot/cold spot areas of exposure change at the subbasin level. We compare the urbanization dynamics in non-hazard areas, single-hazard areas, and multiple-hazard areas, mainly focusing on the urban agglomerations in China. Finally, we discuss the findings and their policy implications.

\subsection{Results}

Based on the data for the year 2015, we found that $20 \%$, $23 \%$, and $32 \%$ of the country's population, built-up land, and cropland, respectively, were within the NHAs for all hazard types. Most of China's population (80\%), built-up land $(77 \%)$, and cropland (68\%) were suffering from at least one type of hazard. Approximately $4 \%$ of population, $3 \%$ of built-up land, and $3 \%$ of cropland were in the areas exposed to more than three types of hazard. Despite the 
marginal proportion of these areas, their population change rate from 1995 to 2015 was the highest (29\%) as compared to other regions of the country.

At the country level, we also assessed the changes of population and land uses in the NHAs, LF-HAs, and HFHAs for all selected hazard types (Fig. 2; Table 2). Population growth rates were found relatively higher in most hazard-prone areas than in NHAs. In the storm surge hazard areas, the annual growth of population from 1995 to 2015 was 3\% and higher in the LF-HAs and HF-HAs, while it was only less than $1 \%$ in the NHAs. Higher annual growth rates of population were also observed in the flood hazard areas, which were under $1 \%$ in the NHAs and over $1 \%$ in both the LF-HAs and HF-HAs. In the drought and earthquake hazard areas, higher annual growth rates were found mainly in the LF-HAs (more than 1\% for both hazard types). In the landslide hazard areas, annual population growth was higher in the HF-HAs (1.2\%) and NHAs (1\%) than in the LF-HAs (less than $1 \%$ ).

Due to the rapid urbanization processes, the built-up land area of China had more than doubled by 2015 as compared to the built-up area in 1995. The LF-HAs and HF-HAs for the storm surge hazard are also the most prosperous regions in China. However, the built-up land growth in these areas was smaller than NHAs for the storm surge hazard. The annual growth of built-up land was under
$4 \%$ in the LF-HAs and HF-HAs, but over $4 \%$ in the NHAs for the storm surge hazard. Similar results were found in the hazard areas for droughts and floods, in which the NHAs featured the highest annual growth rates of built-up land (approximately 5\% and 4\%, respectively). However, in the hazard areas for earthquakes and landslides, the annual growth rates of built-up land were the highest in the HF-HAs (approximately 5\% and 7\%, respectively).

The total area of cropland in China changed slightly from 1995 to 2015 (a net increase of $73,000 \mathrm{~km}^{2}$ or a growth rate of $3 \%$ ). However, the spatial distributions of cropland loss and gain varied widely from one region to another (Table 3). Regarding cropland loss, the change rates were relatively even among the NHAs, LF-Has, and HF-HAs in the hazard areas for droughts, earthquakes, and landslides, ranging from approximately $13-15 \%$. In the hazard areas for storm surges and floods, the LF-HAs (approximately 18\% and 16\%, respectively) and HF-HAs (17\% and 20\%, respectively) had higher cropland loss rates than the NHAs $(<14 \%$ for both hazard types). From the perspective of cropland gain, the NHAs for storm surges and droughts featured the highest growth rates of approximately $17 \%$ and $22 \%$, respectively. Cropland gained rapidly in the hazard areas for earthquakes, floods, and landslides. The growth rates were the highest in the LFHAs for the flood hazard (21\%) and in the HF-HAs for both

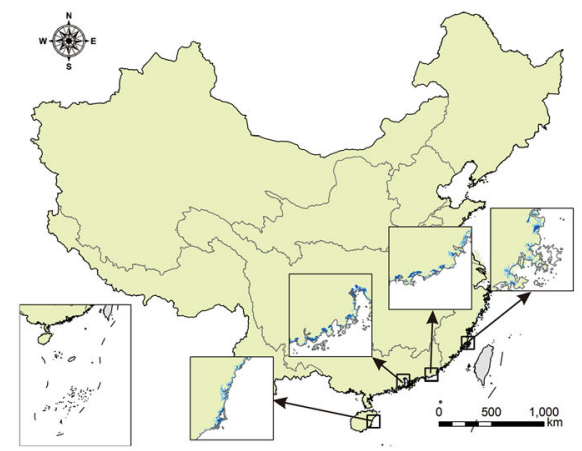

(a) Storm surges

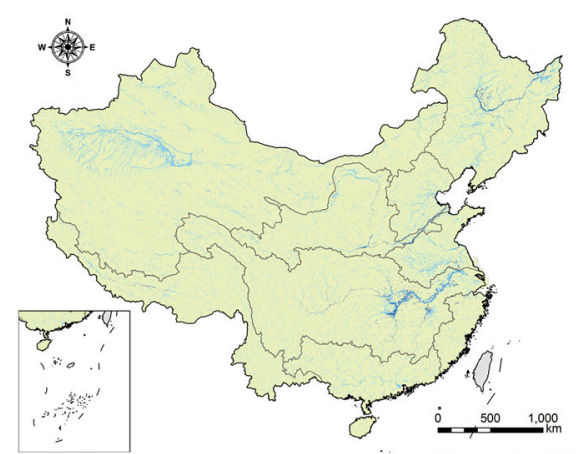

(d) Floods

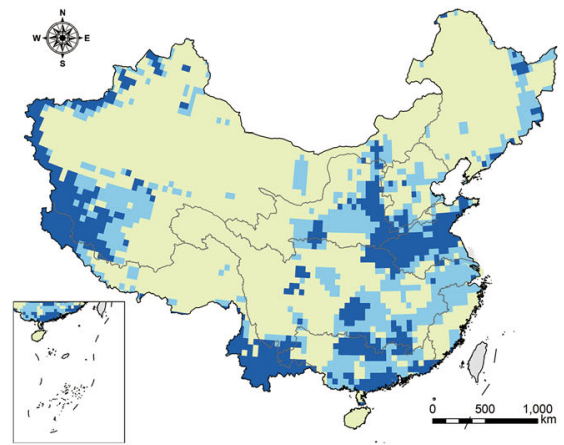

(b) Droughts

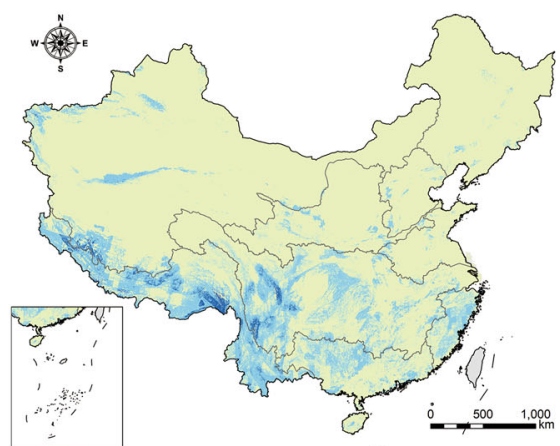

(e) Landslides

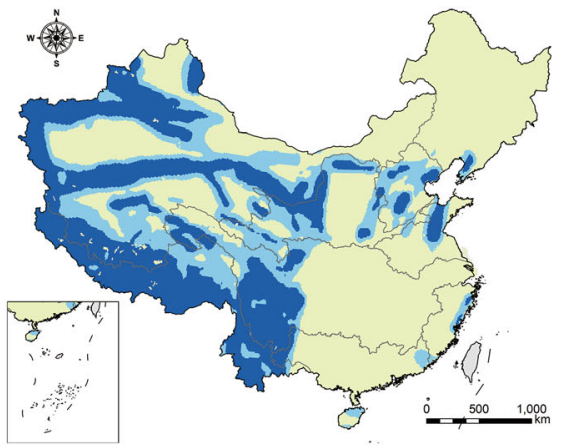

(c) Earthquakes

NHAS

LF-HAs

HF-HAs

No data

Fig. 2 Hazard area classification for a storm surges, b droughts, $\mathbf{c}$ earthquakes, d floods, and e landslides in China in 2015. NHAs Non-hazard areas, $L F-H A s$ low-frequency hazard areas, $H F-H A s$ high-frequency hazard areas 
Table 2 Population and built-up land changes from 1995 to 2015 in the non-hazard areas (NHAs), low-frequency hazard areas (LF-HAs), and high-frequency hazard areas (HF-HAs) for different hazard types in China ( $R$ : overall change rate from 1995 to 2015; $r$ : annual change rate)

\begin{tabular}{|c|c|c|c|c|c|c|}
\hline \multirow[t]{2}{*}{ Hazard } & \multicolumn{3}{|c|}{ Population change $1995-2015$} & \multicolumn{3}{|c|}{ Built-up land change 1995-2015 } \\
\hline & $10^{6}$ & $R(\%)$ & $r(\%)$ & $10^{3}\left(\mathrm{~km}^{2}\right)$ & $R(\%)$ & $r(\%)$ \\
\hline \multicolumn{7}{|c|}{ Storm surges } \\
\hline NHAs & 234.80 & 20.93 & 0.95 & 199.23 & 128.57 & 4.22 \\
\hline LF-HAs & 4.69 & 79.36 & 2.96 & 1.15 & 97.62 & 3.46 \\
\hline HF-HAs & 1.61 & 94.40 & 3.38 & 0.36 & 115.24 & 3.91 \\
\hline \multicolumn{7}{|l|}{ Droughts } \\
\hline NHAs & 79.02 & 17.06 & 0.79 & 92.95 & 150.54 & 4.70 \\
\hline LF-HAs & 103.40 & 27.86 & 1.24 & 60.26 & 122.35 & 4.08 \\
\hline HF-HAs & 56.86 & 19.28 & 0.89 & 47.18 & 104.40 & 3.64 \\
\hline \multicolumn{7}{|c|}{ Earthquakes } \\
\hline NHAs & 157.40 & 19.15 & 0.88 & 131.22 & 120.60 & 4.04 \\
\hline LF-HAs & 54.37 & 31.70 & 1.39 & 38.59 & 133.43 & 4.33 \\
\hline HF-HAs & 29.15 & 21.48 & 0.98 & 30.85 & 164.97 & 4.99 \\
\hline \multicolumn{7}{|l|}{ Floods } \\
\hline NHAs & 210.63 & 20.78 & 0.95 & 176.27 & 131.73 & 4.29 \\
\hline LF-HAs & 26.80 & 26.32 & 1.18 & 22.76 & 109.19 & 3.76 \\
\hline HF-HAs & 3.66 & 26.20 & 1.17 & 1.71 & 95.59 & 3.41 \\
\hline \multicolumn{7}{|c|}{ Landslides } \\
\hline NHAs & 220.14 & 22.51 & 1.02 & 191.11 & 125.92 & 4.16 \\
\hline LF-HAs & 20.78 & 13.86 & 0.65 & 9.62 & 206.41 & 5.76 \\
\hline HF-HAs & 0.35 & 27.08 & 1.21 & 0.07 & 260.00 & 6.61 \\
\hline
\end{tabular}

earthquake and landslide hazards $(22 \%$ and $28 \%$, respectively).

We used hot spot analysis to further illustrate areas with significant changes of population exposure at the subbasin level (Figs. 3 and 4), with the resulting hot spots indicating areas that have had significant exposure increase and vice versa for the resulting cold spots (Table 4). For storm surges, hot/cold spot areas of exposure changes were mainly within the coastal areas of the PRB (Pearl River Basin) and SEB (Southeast Basin) (Figs. 3a and 4a). From 1995 to 2005, population exposure in the storm surge hot spot areas increased by approximately $49 \%$. It increased even further by more than $100 \%$ from 2005 to 2015 , despite the smaller spatial extent of hot spot areas as compared to those found during the period of 1995-2005. The decrease rates of exposure for the storm surge cold spots were relatively similar between 1995-2005 and 2005-2015 ( $-25 \%$ and $-22 \%$, respectively).

The population exposure to droughts in the hot spot areas increased by $23 \%$ from 1995 to 2005 . These areas were mainly in the HURB (Huaihe River Basin), PRB, and parts of the YERB (Yellow River Basin). Some of the hot spots in the HURB and PRB turned into cold spots in 2005-2015. Nevertheless, the total increase rate of exposure in the hot spot areas was still slightly higher than that in the previous period. The decrease rates, however, were only $-6 \%$ and $-12 \%$ in the cold spots for both periods.

For earthquakes, the hot spots of exposure increase were consistently found in the HARB (Haihe River Basin) and parts of the YERB and YARB (Yangtze River Basin) (for example, the Sichuan Basin). The total increase rates were $20 \%$ and 29\%, respectively, in 1995-2005 and 2005-2015. The cold spots were found mainly in the $\mathrm{CB}$ (Continental Basin) in 1995-2005 and in the PRB and SEB in 2005-2015, with total decrease rates of $-23 \%$ and $-20 \%$, respectively.

For the flood hazard, most of the hot spots were consistently observed in the HARB, YARB, and PRB in both 1995-2005 and 2005-2015. However, the increase rate in the hot spots was much higher in 2005-2015 (44\%) than in the previous period $(16 \%)$. The decrease rates were relatively small for both periods, $-12 \%$ or less.

For the landslide hazard, the hot spots were predominantly in the SWB (Southwest Basin), PRB, and the upstream areas of the YARB. The increase rates in these areas were $31 \%$ in $1995-2005$ and $18 \%$ in $2005-2015$. A substantial decrease of $-20 \%$ was found in the cold spots 
Table 3 Cropland loss and gain from 1995 to 2015 in the non-hazard areas (NHAs), low-frequency hazard areas (LF-HAs), and high-frequency hazard areas (HF-HAs) for different hazard types in China $(R$ : overall change rate from 1995 to 2015)

\begin{tabular}{|c|c|c|c|c|}
\hline \multirow[t]{2}{*}{ Hazard } & \multicolumn{2}{|c|}{ Cropland loss 1995-2015 } & \multicolumn{2}{|c|}{ Cropland gain $1995-2015$} \\
\hline & $10^{3}\left(\mathrm{~km}^{2}\right)$ & $R(\%)$ & $10^{3}\left(\mathrm{~km}^{2}\right)$ & $R(\%)$ \\
\hline \multicolumn{5}{|c|}{ Storm surges } \\
\hline NHAs & 346.21 & 13.76 & 420.20 & 16.70 \\
\hline LF-HAs & 0.98 & 17.60 & 0.48 & 8.60 \\
\hline HF-HAs & 0.35 & 17.01 & 0.19 & 9.30 \\
\hline \multicolumn{5}{|l|}{ Droughts } \\
\hline NHAs & 184.59 & 14.32 & 281.96 & 21.88 \\
\hline LF-HAs & 92.62 & 13.46 & 73.80 & 10.73 \\
\hline HF-HAs & 69.92 & 12.81 & 64.90 & 11.89 \\
\hline \multicolumn{5}{|c|}{ Earthquakes } \\
\hline NHAs & 248.72 & 13.51 & 276.58 & 15.02 \\
\hline LF-HAs & 50.52 & 14.88 & 67.85 & 19.99 \\
\hline HF-HAs & 48.24 & 14.03 & 76.41 & 22.22 \\
\hline \multicolumn{5}{|l|}{ Floods } \\
\hline NHAs & 308.90 & 13.53 & 372.51 & 16.31 \\
\hline LF-HAs & 35.56 & 15.77 & 46.39 & 20.57 \\
\hline HF-HAs & 3.08 & 20.19 & 1.97 & 12.92 \\
\hline \multicolumn{5}{|c|}{ Landslides } \\
\hline NHAs & 319.04 & 13.87 & 387.48 & 16.84 \\
\hline LF-HAs & 28.14 & 12.75 & 32.64 & 14.79 \\
\hline HF-HAs & 0.37 & 12.51 & 0.82 & 27.63 \\
\hline
\end{tabular}

in 2005-2015, which was much higher than in the previous period $(-5 \%)$.

The results of the hot spot analysis for changes in builtup land exposure to different hazards are shown in Figs. 5 and 6 and the increase rates are summarized in Table 5. For most of the hazard types, the spatial patterns of hot spots were similar in both 1995-2005 and 2005-2015. The exposure to storm surges increased by more than $50 \%$, predominantly in the hot spot areas of the SEB and PRB (including Hainan Island). Built-up land with increased exposure to droughts was mainly within the HARB, HURB, PRB, and the lower reaches of the YARB, with total increase rates of $24 \%$ in 1995-2005 and 66\% in 2005-2015. The HARB and HURB were also the major areas with increased built-up land exposure to earthquakes. For the flood hazard, built-up land in the YARB and the lower reaches of the YERB had significantly increased exposure in both periods. For landslides, however, hot spots of increased built-up land exposure were only found in 1995-2005, mainly in the PRB, SEB, and SWB, with a total increase rate of approximately $9 \%$.
Figures 7 and 8 depict the spatial distributions of hot/cold spots of changes in cropland exposure to different hazards, and Table 6 shows the change rates in these areas. The results reveal a reverse trend of changes in cropland exposure to storm surges in 1995-2005 and 2005-2015. The hot spots in the PRB in 1995-2005 changed into cold spots in the subsequent period of 2005-2015. Similar results were observed in the SWB for the drought hazard and the HARB for the earthquake hazard. In both periods, the YERB and HURB remained as the major regions of decreased cropland exposure to droughts, while the CB and SWB featured a substantial increase of cropland exposure to earthquakes. For the flood hazard, the cold spots were found mainly in the YARB and HURB. The total decrease rate of exposure in these cold spots was $-12 \%$ in 1995-2005 and - 40\% in 2005-2015. A notable increase of cropland exposure to the flood hazard was observed in the SLRB in 2005-2015, leading to the total increase rates of exposure in hot spots being as high as over 300\% (Table 6). For landslides, areas with increased cropland exposure were consistently found in the SWB (mainly in the Tibetan Plateau). In the YARB, however, the cold spots observed in 1995-2005 changed into hot spots in 2005-2015.

The spatial overlay of the hazard areas reveals that the single-hazard areas and the multi-hazard areas covered $43 \%$ and $26 \%$ of China's territory, respectively. Here multi-hazard areas are defined as areas exposed to two or more hazard types. From 1995 to 2015, the urbanization dynamics, as indicated by the per capita built-up land area (PBA), varied largely among NHAs, single-hazard areas, and multi-hazard areas (Table 7). At the country level, PBA was the highest in the multi-hazard areas in 1995. However, PBA in the NHAs grew astonishingly by approximately $110 \%$ from 1995 to 2015 , outpacing the values of PBA in the single- and multi-hazard areas. The growth rate of PDA was slightly higher in the multi-hazard areas $(76 \%)$ than in the single-hazard areas $(87 \%)$, indicating that population growth was relatively faster in the multi-hazard areas. In the three largest urban agglomerations-Beijing-Tianjin-Hebei region (Jing-Jin-Ji， JJJ), Pearl River Delta (PRD), and Yangtze River Delta (YRD) - the urbanization dynamics from 1995 to 2015 had distinctive features as compared to those observed at the country level (Table 7). In the JJJ region (situated in the HARB), the growth rate of PBA from 1995 to 2015 was more than $110 \%$ in the single-hazard area. In the PRD (situated in the PRB), however, PBA even decreased by $8 \%$ and $16 \%$ in the single-hazard and multi-hazard areas, respectively, indicating that population grew faster than built-up land in the hazard-prone areas. In the YRD (situated in the YARB), PBA grew most rapidly in the multihazard areas (69\%) from 1995 to 2015. 


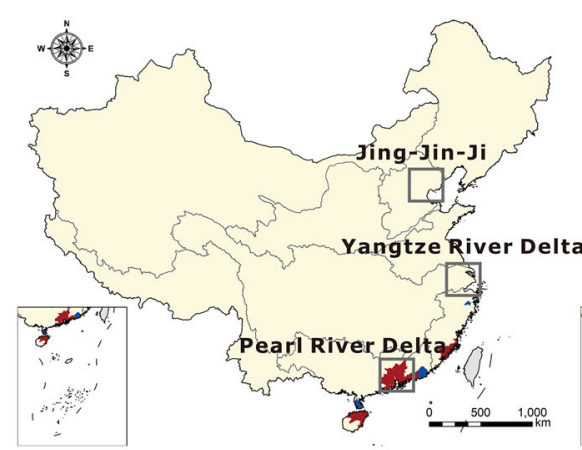

(a) Storm surges

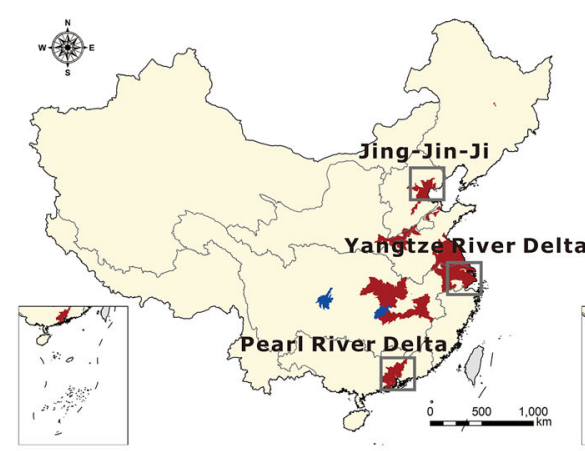

(d) Floods

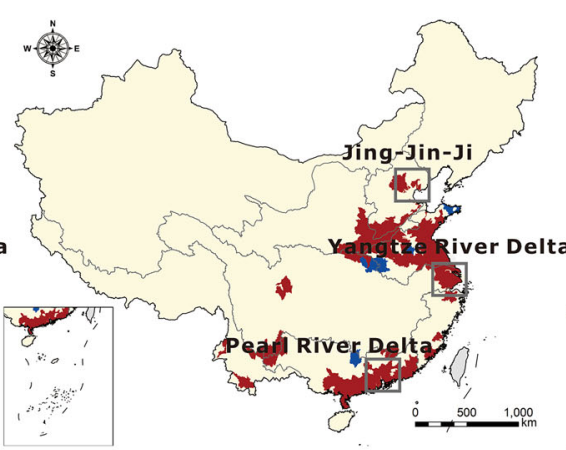

(b) Droughts

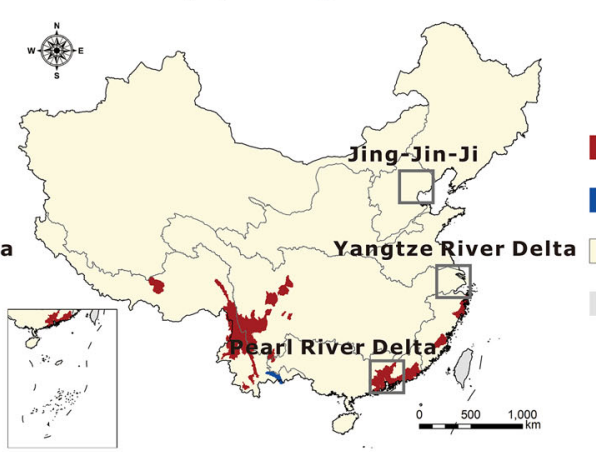

(e) Landslides

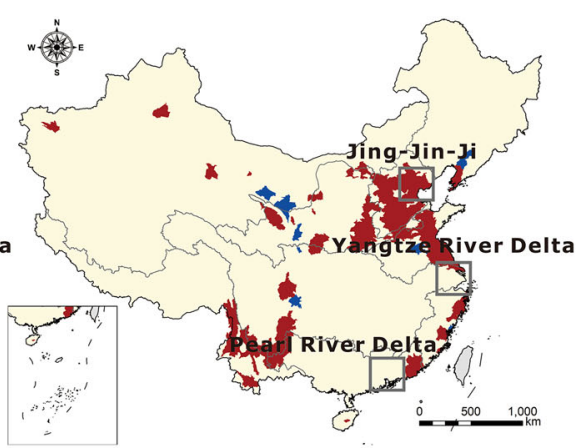

(c) Earthquakes

Fig. $3 \mathrm{Hot} /$ cold spots of changes in population exposure to hazards in China from 1995 to 2005. Jing-Jin-Ji: Beijing-Tianjin-Hebei region

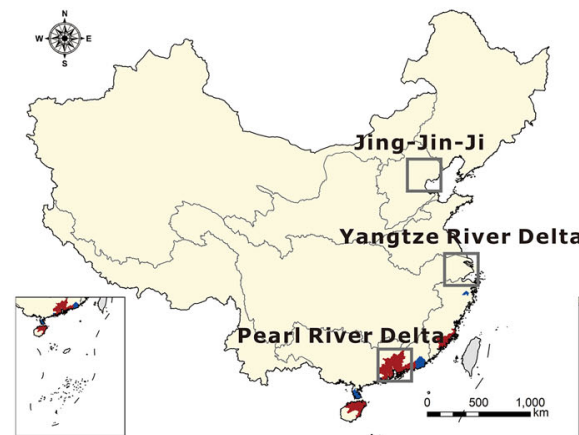

(a) Storm surges

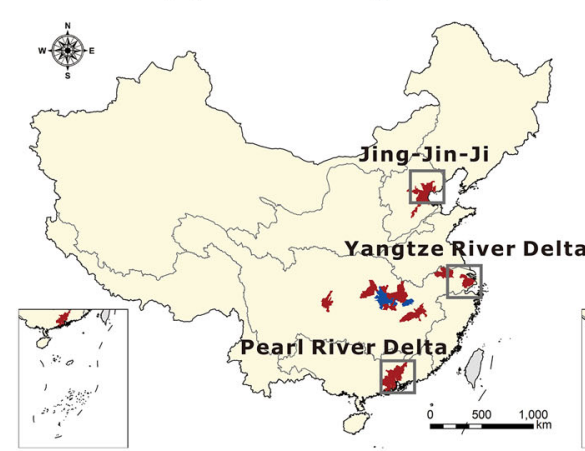

(d) Floods

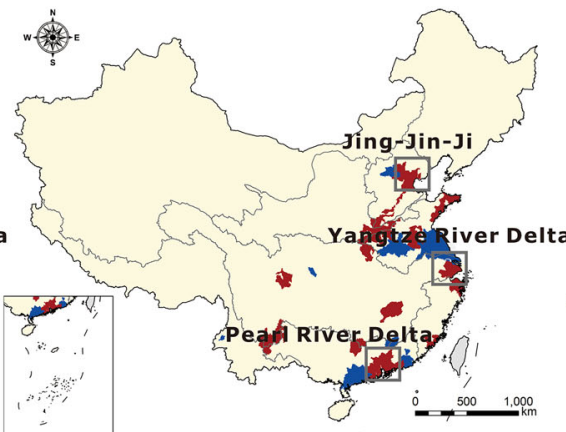

(b) Droughts

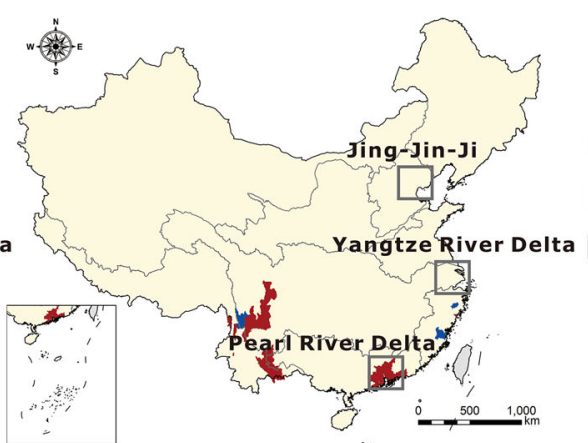

(e) Landslides

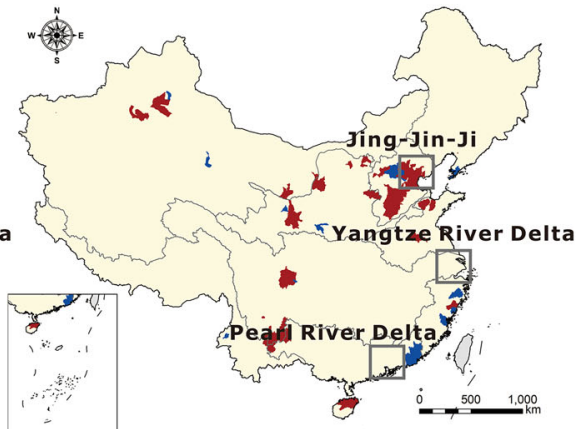

(c) Earthquakes

Hot spots (exposure increase)

Cold spots (exposure decrease)

Not significant

No data

Fig. $4 \mathrm{Hot} /$ cold spots of changes in population exposure to hazards in China from 2005 to 2015. Jing-Jin-Ji: Beijing-Tianjin-Hebei region 
Table 4 Hot/cold spots of changes (\%) in population exposure to different hazards in China from 1995 to 2015

\begin{tabular}{lcccrc}
\hline 1995-2005 & Storm surges & Droughts & Earthquakes & Floods & Landslides \\
\hline Hot spots & 48.80 & 23.02 & 20.38 & 16.43 & -8.74 \\
Cold spots & -24.54 & -5.85 & -23.49 & Floods & Landslides \\
\hline 2005-2015 & Storm surges & Droughts & Earthquakes & 4.83 \\
\hline Hot spots & 107.04 & 25.41 & 28.71 & -12.10 & 18.30 \\
Cold spots & -21.73 & -12.01 & -20.46 & 20.30 \\
\hline
\end{tabular}

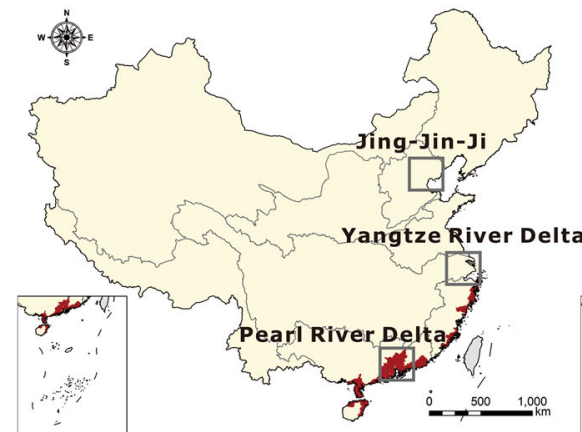

(a) Storm surges

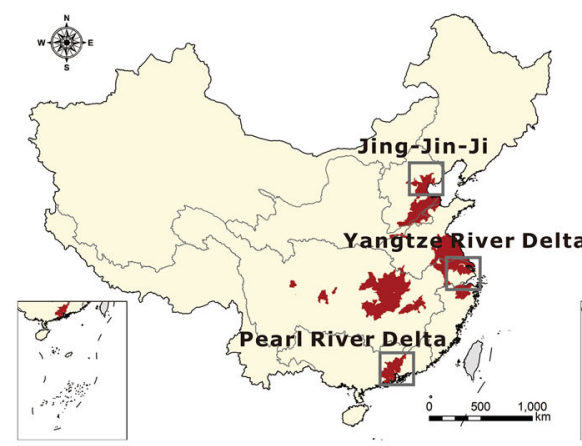

(d) Floods

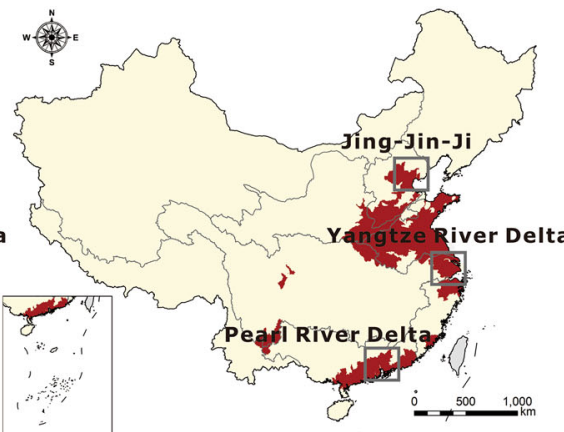

(b) Droughts

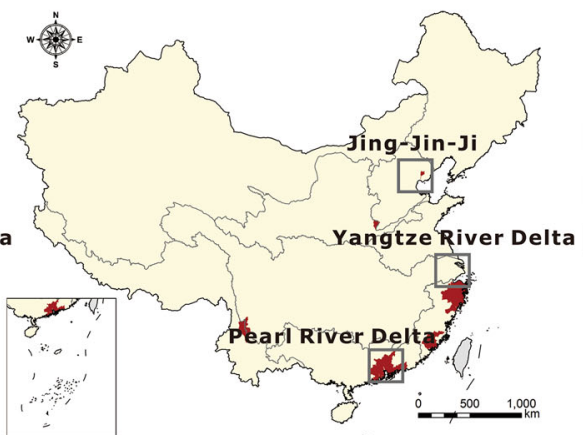

(e) Landslides

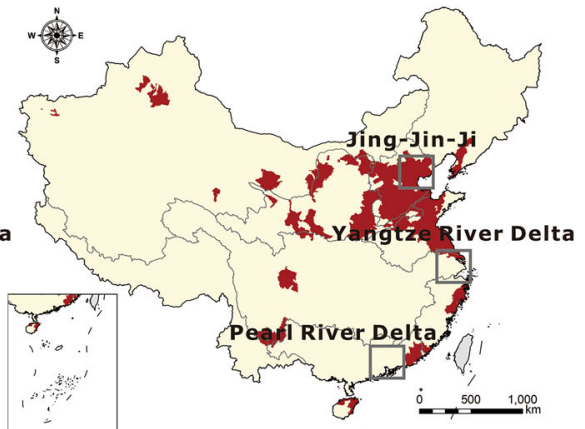

(c) Earthquakes

Hot spots (exposure increase)

Cold spots (exposure decrease)

Not significant

No data

Fig. $5 \mathrm{Hot} / \mathrm{cold}$ spots of changes in built-up land exposure to hazards in China from 1995 to 2005. Jing-Jin-Ji: Beijing-Tianjin-Hebei region

\subsection{Discussion}

The results derived from the above analyses align with the findings in previous studies. Fang et al. (2018) reported that China's population living in floodplains increased at an annual rate of $1.3 \%$ from 1990 to 2015, which was faster than in other regions of the country. Our analyses also yield a similar annual growth rate of approximately $1.2 \%$ in the flood hazard areas from 1995 to 2015 (Table 2). He et al. (2016) found a higher population growth rate in China's hazard areas for earthquakes (over 33\%), as compared to the national average (18\%). Our results show a consistent, albeit slightly lower, population growth trend in the hazard areas for earthquakes (32\% in the LF-HAs and $21 \%$ in the HF-HAs, respectively) (Table 2). Du et al. (2018) highlighted the urban land expansion in the coastal floodplains of China, while our study identified the hot spots of increased built-up land exposure to floods in the coastal areas of East China (Figs. 5d and 6d). Our results also reveal a more rapid growth trend of built-up land in the hazard areas for earthquakes in China (Table 2), which is in line with the findings of a recent study (Huang et al. 2019). From the perspective of cropland, the cold spots of exposure to droughts emerged in the YERB and HURB (Figs. $7 \mathrm{~b}$ and $8 \mathrm{~b}$ ), largely owing to the urban encroachment on cropland. However, a substantial increase of cropland area also occurred in the hazard areas for droughts (including LF-HAs and HF-HAs) (Table 2), implying more cropland area exposed to the drought hazard. This result is also in accordance with previous literature ( $\mathrm{Li}$ et al. 2015; $\mathrm{Xu}$ et al. 2018).

The results of our analyses also reveal that from 1995 to 2015 population growth was more rapid in the hazard areas for storm surges, while built-up land expansion was slower 


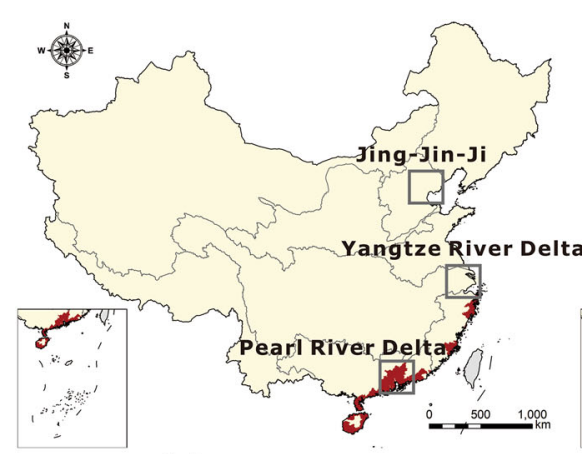

(a) Storm surges

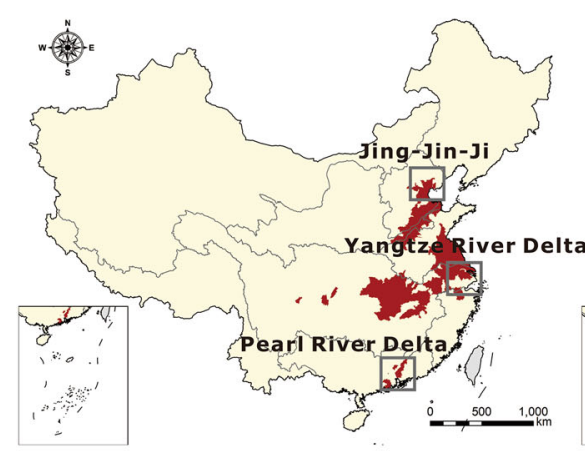

(d) Floods

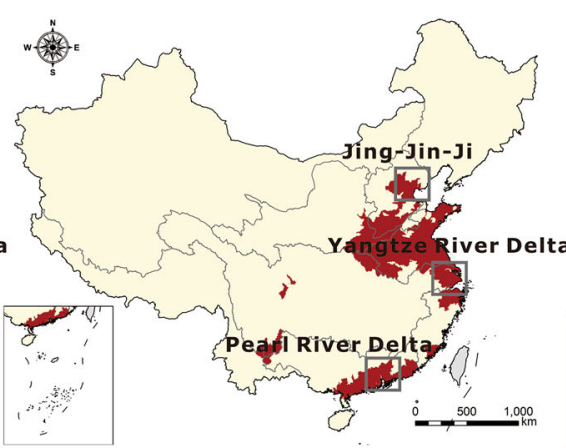

(b) Droughts

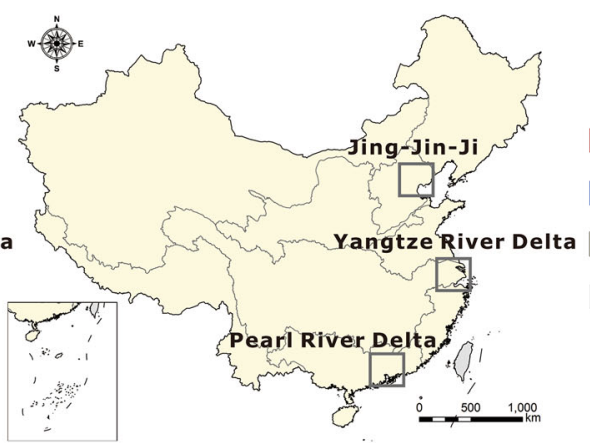

(e) Landslides

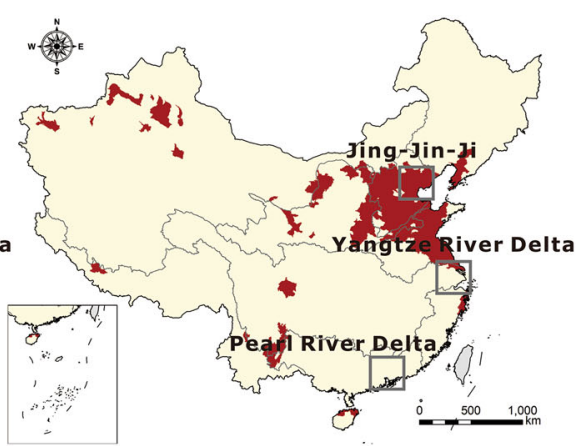

(c) Earthquakes

Fig. $6 \mathrm{Hot} /$ cold spots of changes in built-up land exposure to hazards in China from 2005 to 2015. Jing-Jin-Ji: Beijing-Tianjin-Hebei region

Table 5 Hot spots of changes (\%) in built-up land exposure to different hazards in China from 1995 to 2015

\begin{tabular}{llllll}
\hline & Storm surges & Droughts & Earthquakes & Floods & Landslides \\
\hline $1995-2005$ & 56.80 & 23.50 & 26.22 & 23.75 & 8.89 \\
$2005-2015$ & 53.68 & 65.88 & 90.53 & 61.96 & - \\
\hline
\end{tabular}

in the hazard areas for storm surges than in other hazard areas of inland China (Fig. 2; Table 2). The per capita built-up land area in the multi-hazard areas of the PRD even declined from 1995 to 2015 (Table 7). These results are confirmed by the findings of previous studies. Empirical literature found that rapid growth of population in the coastal cities was related to the greater job opportunities and higher incomes in these cities (Ma et al. 2016; Deng et al. 2008). Moreover, the efficiency of built-up land in the coastal cities was found greater than in the inland cities, resulting in a relatively lower level of sprawl of built-up land (Gao et al. 2016). From the perspective of disaster risk reduction, the sprawling of built-up land may increase the difficulty and construction costs to deploy and manage hazard-resistant infrastructure.

Our analysis identified hot spot areas with significant increase of exposure to multiple hazards simultaneously (Figs. 5, 6, 7 and 8). Population and built-up land in the PRB were increasingly exposed to storm surges, floods, and landslides. The HARB and HURB, which are in the North China Plain, experienced consistent increase of population and built-up land exposure to droughts and earthquakes. Many previous studies have reported the substantial challenges facing these regions due to the occurrence of multiple hazard events (Wang et al. 2018; Zhang et al. 2018, 2019). Regions with multi-hazards are often suffering from more severe damages. Guangdong Province in the PRB, for instance, is heavily exposed to multiple hazards of storm surges (4 million people affected and RMB 6 billion yuan of economic loss annually), floods (2.4 million people affected and RMB 2.8 billion yuan of economic loss annually), and geological hazards such as landslides (causing RMB 0.4 billion yuan of economic loss between 2011 and 2015) (China Meteorological Administration 2015; Department of Natural Resources of Guangdong Province 2016). In the capital city of Guangdong Province, Guangzhou, geological hazards caused RMB 0.6 billion yuan of economic loss from 1992 to 2015, while 


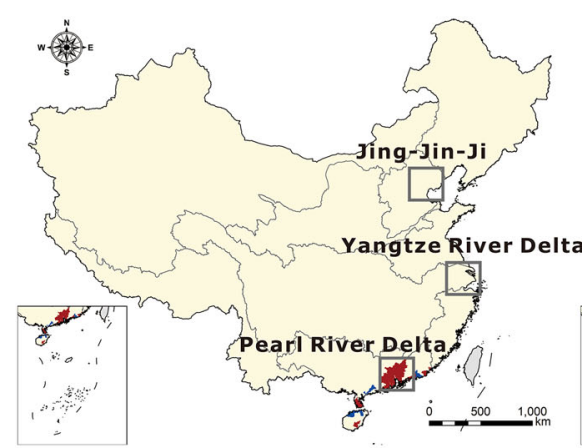

(a) Storm surges

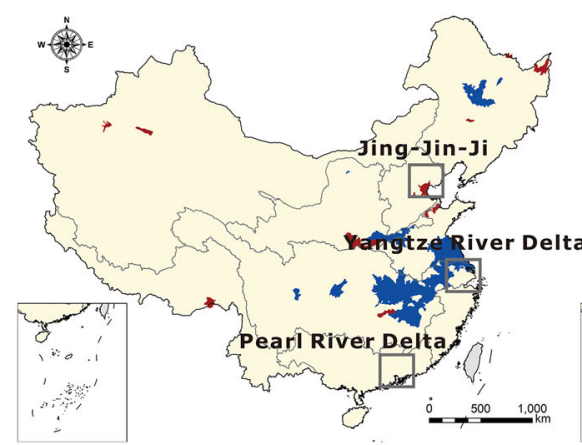

(d) Floods

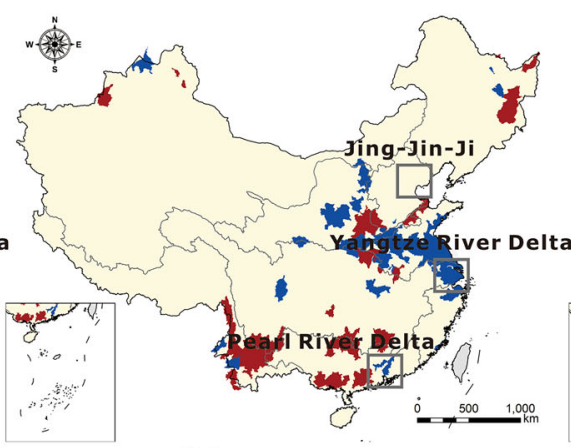

(b) Droughts

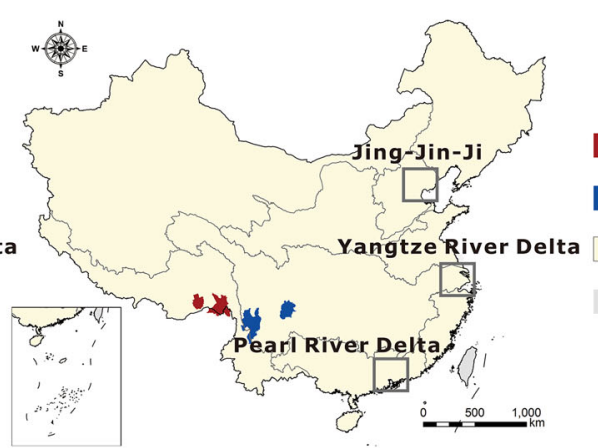

(e) Landslides

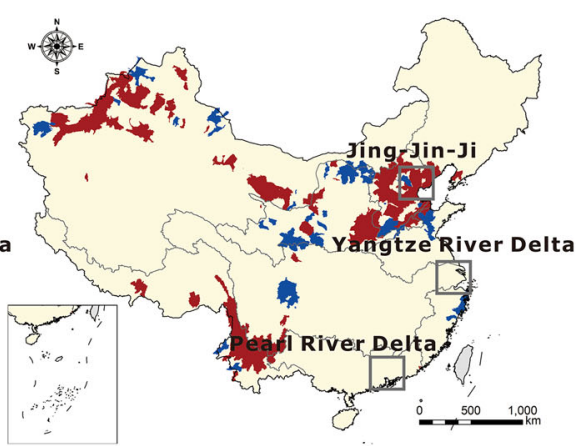

(c) Earthquakes

Fig. $7 \mathrm{Hot} /$ cold spots of changes in cropland exposure to hazards in China from 1995 to 2005. Jing-Jin-Ji: Beijing-Tianjin-Hebei region

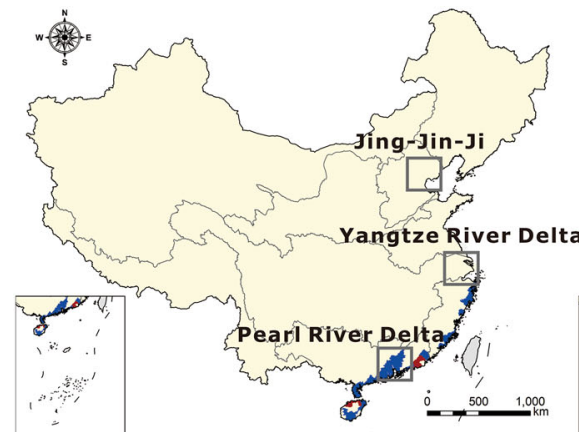

(a) Storm surges

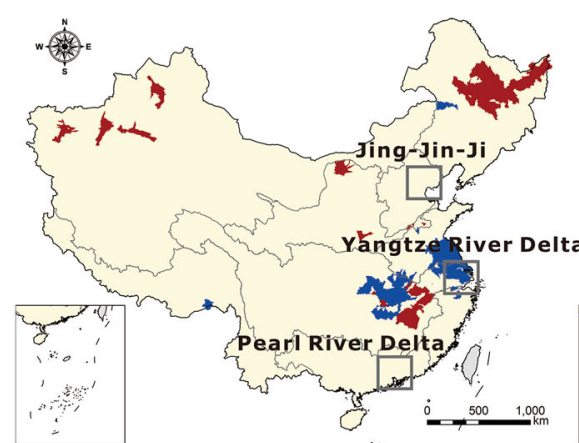

(d) Floods

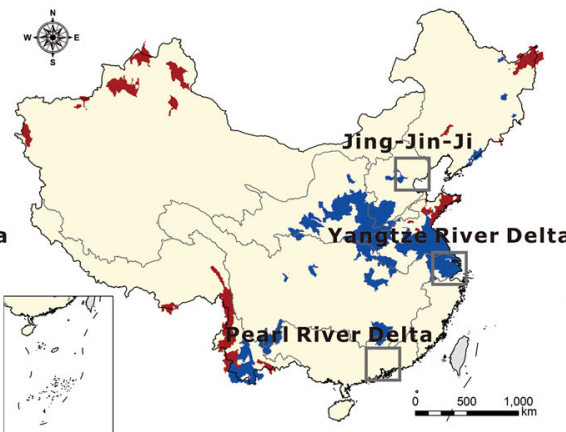

(b) Droughts

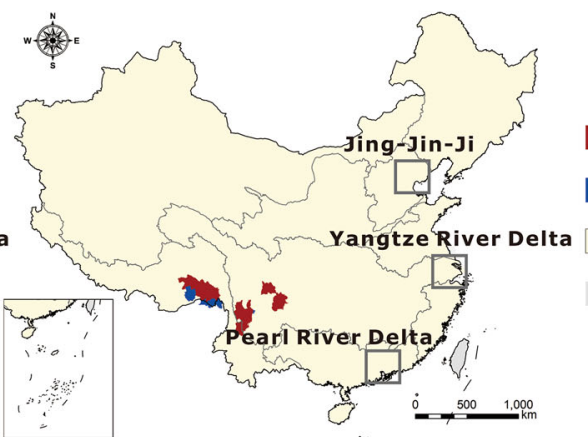

(e) Landslides

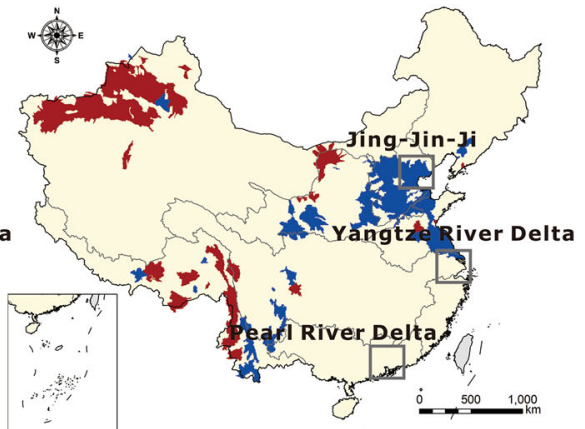

(c) Earthquakes
Hot spots (exposure increase)

Cold spots (exposure decrease)

No data

Hot spots (exposure increase)

Cold spots (exposure decrease)

Not significant

No data

Fig. $8 \mathrm{Hot} /$ cold spots of changes in cropland exposure to hazards in China from 2005 to 2015. Jing-Jin-Ji: Beijing-Tianjin-Hebei region

floods led to an estimated annual loss of GDP of $0.3 \%$ (Shi et al. 2018). This evidence strongly indicates the importance of integrated disaster management for these regions to reduce the risks of multiple hazards, especially in the context of ongoing urbanization. However, in many rapidly developing regions of China, the disaster risk reduction 
Table 6 Hot/cold spots of changes (\%) in cropland exposure to different hazards in China from 1995 to 2015

\begin{tabular}{lccccc}
\hline 1995-2005 & Storm surges & Droughts & Earthquakes & Floods & 26.18 \\
\hline Hot spots & 7.92 & 13.49 & 12.69 & -11.79 & -30.83 \\
Cold spots & -12.23 & -3.46 & -5.05 & Fandslides \\
\hline $2005-2015$ & Storm surges & Droughts & Earthquakes & Floods & Landslides \\
\hline Hot spots & 8.90 & 11.71 & 29.69 & 305.54 & 78.78 \\
Cold spots & -13.91 & -5.02 & -5.45 & -39.88 & -33.41 \\
\hline
\end{tabular}

Table 7 Per capita built-up land area $\left(\mathrm{hm}^{2}\right)$ in different hazard-prone areas of China and three major urban agglomerations for 1995 and 2015

\begin{tabular}{|c|c|c|c|c|c|c|c|c|}
\hline & \multicolumn{2}{|l|}{ China } & \multicolumn{2}{|l|}{ JJJ } & \multicolumn{2}{|l|}{ PRD } & \multicolumn{2}{|l|}{ YRD } \\
\hline & 1995 & 2015 & 1995 & 2015 & 1995 & 2015 & 1995 & 2015 \\
\hline Non-hazard area & 1.44 & 3.01 & 1.73 & 4.09 & 1.32 & 1.76 & 1.86 & 2.66 \\
\hline Single-hazard area & 1.35 & 2.53 & 1.84 & 3.92 & 1.78 & 1.63 & 1.62 & 2.54 \\
\hline Multi-hazard area & 1.59 & 2.80 & 2.13 & 3.26 & 1.74 & 1.47 & 1.26 & 2.13 \\
\hline
\end{tabular}

$J J J$ Jing-Jin-Ji (Beijing-Tianjin-Hebei region), PRD pearl river delta, and $Y R D$ Yangtze river delta

plans and laws are not always successful in limiting development in hazard areas (Kim and Rowe 2013). The fragmented and overlapping structure of disaster risk governance in China also hampers the effective implementation of risk reduction policies (Du et al. 2018). A more adaptive and coordinating organization of governance is necessary to regulate future urban development and improve the resilience to natural hazards (Cai et al. 2018; Du et al. 2018).

Overall, our study provides empirical findings of the changing exposure to multiple hazards in China, and form a foundation for the design of protection and adaption strategies. However, there are several limitations in this study. First, we assumed the hazard frequency and related classifications to be constant throughout the study period of 1995-2015. Future work should factor in the dynamics of climate change and estimate the potential changes for different hazards. Second, we focused mainly on exposure that does not necessarily translate into risk (Hanson et al. 2011). Future work may also incorporate factors such as gross domestic product (GDP) and infrastructure spending of governments to assess potential risk and resilience as well (Jongman et al. 2012; Cai et al. 2018). Third, it is also feasible to enhance the analysis with future projections of population and land uses. Several recent studies have provided their estimations of future population and land use change scenarios (Jiang and O'Neill 2017; Li et al. 2017; Liu et al. 2017; Chen et al. 2019). Linking these results with potential trends of hazards is, therefore, useful to help mitigate future losses induced by hazard events. Furthermore, a new trend has emerged in recent literature, that is, an increasing use of social media or Internet open data for hazard related research (Lin et al. 2018). Social media data can provide rich information on human activities and the spatial organization of socioeconomic functions (Chen et al. 2017), and offer promising potential to carry out more accurate estimations of vulnerability and resilience to natural hazards at an even finer resolution.

\section{Conclusion}

In this study, we assessed the exposure of population, builtup land, and cropland to multiple hazard types in China from 1995 to 2015 . We found that $26 \%$ of China's territory is exposed to two or more hazard types. Most of the population, built-up land, and cropland in China were in the areas that are subjected to at least one type of hazard. The results reveal the rapid changes of population, built-up land, and cropland in China's hazard-prone areas from 1995 to 2015. At the country level, the population growth rates in the LF-HAs and HF-HAs were higher than those in the NHAs. Built-up land expansion was faster in the HFHAs for earthquakes (5\% annually) and landslides (7\% annually) than other hazard types. The total area of China's cropland increased by 3\% from 1995 to 2015 . Despite such a small amount of overall change, the spatial patterns of cropland loss and expansion varied among hazard-prone areas. The cropland loss rates were the highest in the HFHAs for floods, while the cropland growth rates were the highest in the HF-HAs for both earthquake and landslide hazards. By using hot spot analysis, we depicted the 
subbasin-level hot/cold spot areas of exposure changes. The results suggest that in the PRB, the exposure of population and built-up land to hazards of storm surges, droughts, floods, and landslides increased significantly from 1995 to 2015. In the HARB and HURB, population and built-up land exposure to the hazards of droughts and earthquakes also increased rapidly from 1995 to 2015. These empirical findings are important for the effective implementation of strategies and policies that aim at improving the resilience to multiple hazards. In our future work, we will incorporate climate factors such that the changes of hazard frequency and intensity caused by climate changes can be modeled. Moreover, we will move beyond the exposure analysis to the assessment of risk and resilience by accounting more socioeconomic factors and the projections of population and land uses.

Acknowledgements We sincerely thank the anonymous reviewers for their useful comments and suggestions. This research was supported by the National Key R\&D Program of China (2017YFA0604401), the National Natural Science Foundation of China (Grant Nos. 41871306 and 41601420), the Key National Natural Science Foundation of China (Grant No. 41531176), and the research fund from Shenzhen Key Laboratory of Spatial Smart Sensing and Service.

Open Access This article is licensed under a Creative Commons Attribution 4.0 International License, which permits use, sharing, adaptation, distribution and reproduction in any medium or format, as long as you give appropriate credit to the original author(s) and the source, provide a link to the Creative Commons licence, and indicate if changes were made. The images or other third party material in this article are included in the article's Creative Commons licence, unless indicated otherwise in a credit line to the material. If material is not included in the article's Creative Commons licence and your intended use is not permitted by statutory regulation or exceeds the permitted use, you will need to obtain permission directly from the copyright holder. To view a copy of this licence, visit http://creativecommons. org/licenses/by/4.0/.

\section{References}

Blöschl, G., J. Hall, J. Parajka, R.A. Perdigão, B. Merz, B. Arheimer, G.T. Aronica, A. Bilibashi, O. Bonacci, and M. Borga. 2017. Changing climate shifts timing of European floods. Science 357(6351): 588-590.

Cai, J., M. Kummu, V. Niva, J.H. Guillaume, and O. Varis. 2018. Exposure and resilience of China's cities to floods and droughts: A double-edged sword. International Journal of Water Resources Development 34(4): 547-565.

Chen, Y., X. Li, X. Liu, Y. Zhang, and M. Huang. 2019. Teleconnecting China's future urban growth to impacts on ecosystem services under the shared socioeconomic pathways. Science of the Total Environment 652: 765-779.

Chen, Y., X. Liu, X. Li, X. Liu, Y. Yao, G. Hu, X. Xu, and F. Pei. 2017. Delineating urban functional areas with building-level social media data: A dynamic time warping (DTW) distance based k-medoids method. Landscape and Urban Planning 160: $48-60$.
Cheng, G., and X. Li. 2015. Integrated research methods in watershed science. Science China Earth Sciences 58(7): 1159-1168.

China Meteorological Administration. 2015. Meterological hazards migitagion plan of Guangdong Province (2011-2020). http:// www.cma.gov.cn/2011xzt/2015zt/20150702/2015070202/ 201507020202/201507/t20150702_286796.html/. Accessed 17 Jun 2019 (in Chinese).

CRED (Centre for Research on the Epidemiology of Disasters). 2019. International disaster database. Brussels: Université Catholique de Louvain. https://www.emdat.be/emdat_db/. Accessed 28 Feb 2019.

Cui, P., Y.-M. Lin, and C. Chen. 2012. Destruction of vegetation due to geo-hazards and its environmental impacts in the Wenchuan earthquake areas. Ecological Engineering 44: 61-69.

Deng, X., J. Huang, S. Rozelle, and E. Uchida. 2008. Growth, population and industrialization, and urban land expansion of China. Journal of Urban Economics 63(1): 96-115.

Department of Natural Resources of Guangdong Province. 2016. Geological hazards mitigation of Guangdong Province. http://nr. gd.gov.cn/attachment/0/187/187128/525517.pdf. Accessed 17 Jun 2019 (in Chinese).

Du, S., C. He, Q. Huang, and P. Shi. 2018. How did the urban land in floodplains distribute and expand in China from 1992-2015? Environmental Research Letters 13(3): Article 034018.

Fang, Y., S. Du, P. Scussolini, J. Wen, C. He, Q. Huang, and J. Gao. 2018. Rapid population growth in Chinese floodplains from 1990 to 2015. International Journal of Environmental Research and Public Health 15(8): Article 1602.

Gao, B., Q. Huang, C. He, Z. Sun, and D. Zhang. 2016. How does sprawl differ across cities in China? A multi-scale investigation using nighttime light and census data. Landscape and Urban Planning 148: 89-98.

Güneralp, B., İ. Güneralp, and Y. Liu. 2015. Changing global patterns of urban exposure to flood and drought hazards. Global Environmental Change 31: 217-225.

Han, W., C. Liang, B. Jiang, W. Ma, and Y. Zhang. 2016. Major natural disasters in China, 1985-2014: Occurrence and damages. International Journal of Environmental Research and Public Health 13(11): Article 1118.

Hanson, S., R. Nicholls, N. Ranger, S. Hallegatte, J. Corfee-Morlot, C. Herweijer, and J. Chateau. 2011. A global ranking of port cities with high exposure to climate extremes. Climatic Change 104(1): 89-111.

He, B., J. Wu, A. Lv, X. Cui, L. Zhou, M. Liu, and L. Zhao. 2013. Quantitative assessment and spatial characteristic analysis of agricultural drought risk in China. Natural Hazards 66(2): $155-166$.

He, C., Q. Huang, Y. Dou, W. Tu, and J. Liu. 2016. The population in China's earthquake-prone areas has increased by over 32 million along with rapid urbanization. Environmental Research Letters 11(7): Article 074028.

Holzer, T.L., and J.C. Savage. 2013. Global earthquake fatalities and population. Earthquake Spectra 29(1): 155-175.

Hualou, L., and Z. Jian. 2010. Farmland destroyed by natural hazards in China: Spatio-temporal pattern and integrated prevention and treatment system. Disaster Advances 3(4): 592-597.

Huang, J., H. Yu, A. Dai, Y. Wei, and L. Kang. 2017. Drylands face potential threat under $2^{\circ} \mathrm{C}$ global warming target. Nature Climate Change 7(6): Article 417.

Huang, Q., S. Meng, C. He, Y. Dou, and Q. Zhang. 2019. Rapid urban land expansion in earthquake-prone areas of China. International Journal of Disaster Risk Science 10(1): 43-56.

Jaimes, M.A., E. Reinoso, and L. Esteva. 2015. Risk analysis for structures exposed to several multi-hazard sources. Journal of Earthquake Engineering 19(2): 297-312. 
Jiang, B. 2013. Head/tail breaks: A new classification scheme for data with a heavy-tailed distribution. The Professional Geographer 65(3): 482-494.

Jiang, B. 2015. Geospatial analysis requires a different way of thinking: The problem of spatial heterogeneity. GeoJournal 80(1): 1-13.

Jiang, L., and B.C. O’Neill. 2017. Global urbanization projections for the shared socioeconomic pathways. Global Environmental Change 42: 193-199.

Jongman, B., P.J. Ward, and J.C. Aerts. 2012. Global exposure to river and coastal flooding: Long term trends and changes. Global Environmental Change 22(4): 823-835.

Kappes, M.S., M. Keiler, K. von Elverfeldt, and T. Glade. 2012. Challenges of analyzing multi-hazard risk: A review. Natural Hazards 64(2): 1925-1958.

Kim, S., and P.G. Rowe. 2013. Are master plans effective in limiting development in China's disaster-prone areas? Landscape and Urban Planning 111: 79-90.

Komendantova, N., R. Mrzyglocki, A. Mignan, B. Khazai, F. Wenzel, A. Patt, and K. Fleming. 2014. Multi-hazard and multi-risk decision-support tools as a part of participatory risk governance: Feedback from civil protection stakeholders. International Journal of Disaster Risk Reduction 8: 50-67.

Lerner-Lam, A. 2007. Assessing global exposure to natural hazards: Progress and future trends. Environmental Hazards 7(1): 10-19.

Li, X., G. Chen, X. Liu, X. Liang, S. Wang, Y. Chen, F. Pei, and X. $\mathrm{Xu}$. 2017. A new global land-use and land-cover change product at a $1-\mathrm{km}$ resolution for 2010 to 2100 based on humanenvironment interactions. Annals of the American Association of Geographers 107(5): 1040-1059.

Li, Y., H. Huang, H. Ju, E. Lin, W. Xiong, X. Han, H. Wang, Z. Peng, Y. Wang, and J. Xu. 2015. Assessing vulnerability and adaptive capacity to potential drought for winter-wheat under the RCP 8.5 scenario in the Huang-Huai-Hai Plain. Agriculture, Ecosystems \& Environment 209: 125-131.

Liang, P., W. Xu, Y. Ma, X. Zhao, and L. Qin. 2017. Increase of elderly population in the rainstorm hazard areas of China. International Journal of Environmental Research and Public Health 14 (9): Article 963.

Lin, T., X. Liu, J. Song, G. Zhang, Y. Jia, Z. Tu, Z. Zheng, and C. Liu. 2018. Urban waterlogging risk assessment based on internet open data: A case study in China. Habitat International 71: $88-96$.

Liu, X., G. Hu, Y. Chen, X. Li, X. Xu, S. Li, F. Pei, and S. Wang. 2018. High-resolution multi-temporal mapping of global urban land using landsat images based on the google earth engine platform. Remote Sensing of Environment 209: 227-239.

Liu, X., X. Liang, X. Li, X. Xu, J. Ou, Y. Chen, S. Li, S. Wang, and F. Pei. 2017. A future land use simulation model (FLUS) for simulating multiple land use scenarios by coupling human and natural effects. Landscape and Urban Planning 168: 94-116.

Liu, Z., and S. Sun. 2009. The disaster of May 12th Wenchuan earthquake and its influence on debris flows. Journal of Geography and Geology 1(1): 26-30.

Lo, A.Y., B. Xu, F.K. Chan, and R. Su. 2015. Social capital and community preparation for urban flooding in China. Applied Geography 64: 1-11.

Ma, Q., C. He, and J. Wu. 2016. Behind the rapid expansion of urban impervious surfaces in China: Major influencing factors revealed by a hierarchical multiscale analysis. Land Use Policy 59: $434-445$.

Masutomi, Y., Y. Inui, K. Takahashi, and Y. Matsuoka. 2009. Development of highly accurate global polygonal drainage basin data. Hydrological Processes: An International Journal 23(4): $572-584$.
Miao, C., J. Teng, J. Wang, and P. Zhou. 2018. Population vulnerability assessment of geological disasters in China using CRITIC-GRA methods. Arabian Journal of Geosciences 11(11): Article 268.

Ming, X., W. Xu, Y. Li, J. Du, B. Liu, and P. Shi. 2015. Quantitative multi-hazard risk assessment with vulnerability surface and hazard joint return period. Stochastic Environmental Research and Risk Assessment 29(1): 35-44.

Nadim, F., C. Jaedicke, H. Smebye, and B. Kalsnes. 2013. Assessment of global landslide hazard hotspots. In Landslides: Global risk preparedness, ed. K. Sassa, B. Rouhban, S. Briceño, M. McSaveney, and B. He, 59-71. Berlin: Springer.

Neumann, B., A.T. Vafeidis, J. Zimmermann, and R.J. Nicholls. 2015. Future coastal population growth and exposure to sea-level rise and coastal flooding - a global assessment. PloS One 10(3): Article e0118571.

Peduzzi, P., H. Dao, C. Herold, and F. Mouton. 2009. Assessing global exposure and vulnerability towards natural hazards: The disaster risk index. Natural Hazards and Earth System Sciences 9(4): 1149-1159.

Pei, W., Q. Fu, D. Liu, T.-X. Li, K. Cheng, and S. Cui. 2018. Spatiotemporal analysis of the agricultural drought risk in Heilongjiang Province, China. Theoretical and Applied Climatology 133(1-2): 151-164.

Rao, E., Y. Xiao, Z. Ouyang, and H. Zheng. 2016. Changes in ecosystem service of soil conservation between 2000 and 2010 and its driving factors in southwestern China. Chinese Geographical Science 26(2): 165-173.

Sajjad, M., Y. Li, Z. Tang, L. Cao, and X. Liu. 2018. Assessing hazard vulnerability, habitat conservation, and restoration for the enhancement of mainland China's coastal resilience. Earth's Future 6(3): 326-338.

Shi, P., W. Xu, T. Ye, S. Yang, L. Liu, W. Fang, K. Liu, N. Li, and M. Wang. 2015. Mapping multi-hazard risk of the world. In World atlas of natural disaster risk, ed. P. Shi, and R. Kasperson, 287-306. Berlin: Springer.

Shi, Y., G. Zhai, S. Zhou, Y. Lu, W. Chen, and H. Liu. 2018. How can cities adapt to a multi-disaster environment? Empirical research in Guangzhou (China). International Journal of Environmental Research and Public Health 15(11): Article 2453.

Sun, H., Y. Wang, J. Chen, J. Zhai, C. Jing, X. Zeng, H. Ju, N. Zhao, M. Zhan, and L. Luo. 2017. Exposure of population to droughts in the Haihe River Basin under global warming of 1.5 and $2.0^{\circ} \mathrm{C}$ scenarios. Quaternary International 453: 74-84.

Tian, Q., D.G. Brown, S. Bao, and S. Qi. 2015. Assessing and mapping human well-being for sustainable development amid flood hazards: Poyang Lake Region of China. Applied Geography 63: 66-76.

UNDESA (United Nations Department of Economic and Social Affairs). 2016. The world's cities in 2016. New York: United Nations.

UNISDR (United Nations International Strategy for Disaster Reduction). 2012. Impacts of disasters since the 1992 Rio de Janeiro Earth Summit. Rio de Janeiro: United Nations.

UNISDR (United Nations International Strategy for Disaster Reduction). 2015. Making development sustainable: The future of disaster risk management (Global Assessment Report on Disaster Risk Reduction). Geneva: United Nations.

Wang, Z., R. Zhong, C. Lai, Z. Zeng, Y. Lian, and X. Bai. 2018. Climate change enhances the severity and variability of drought in the Pearl River Basin in South China in the 21st century. Agricultural and Forest Meteorology 249: 149-162.

Wu, J., C. Wang, X. He, X. Wang, and N. Li. 2017. Spatiotemporal changes in both asset value and GDP associated with seismic exposure in China in the context of rapid economic growth from 
1990 to 2010. Environmental Research Letters 12(3): Article 034002.

Wu, Z., H. Xu, Y. Li, L. Wen, J. Li, G. Lu, and X. Li. 2018. Climate and drought risk regionalisation in China based on probabilistic aridity and drought index. Science of the Total Environment 612: 513-521.

Xu, H.-J., X.-P. Wang, C.-Y. Zhao, and X.-M. Yang. 2018. Diverse responses of vegetation growth to meteorological drought across climate zones and land biomes in northern China from 1981 to 2014. Agricultural and Forest Meteorology 262: 1-13.

Yang, S., S. He, J. Du, and X. Sun. 2015. Screening of social vulnerability to natural hazards in China. Natural Hazards 76(1): $1-18$.
Yin, Y., B. Li, W. Wang, L. Zhan, Q. Xue, Y. Gao, N. Zhang, H. Chen, T. Liu, and A. Li. 2016. Mechanism of the December 2015 catastrophic landslide at the Shenzhen landfill and controlling geotechnical risks of urbanization. Engineering 2(2): 230-249.

Zhang, Q., X. Gu, V.P. Singh, P. Shi, and P. Sun. 2018. More frequent flooding? Changes in flood frequency in the Pearl River basin, China, since 1951 and over the past 1000 years. Hydrology and Earth System Sciences 22(5): 2637-2653.

Zhang, X., J. Song, J. Peng, and J. Wu. 2019. Landslides-oriented urban disaster resilience assessment-A case study in ShenZhen, China. Science of the Total Environment 661: 95-106. 